\title{
Differentiated threat and the genesis of prejudice. Group-specific antecedents of homonegativity, Islamophobia, anti-Semitism and anti-immigrant attitudes
}

\author{
Bart Meuleman \\ Institute for Social and Political Opinion Research (ISPO) / Centre for Sociological Research \\ (CeSO), University of Leuven \\ Koen Abts \\ Centre d'Etude de l'Opinion (CLEO), University of Liège \\ Institute for Social and Political Opinion Research (ISPO) / Centre for Sociological Research \\ (CeSO), University of Leuven \\ Koen Slootmaeckers \\ School of Politics and International Relations, Queen Mary University of London \& Leuven \\ International and European Studies (LINES), University of Leuven \\ Cecil Meeusen \\ Institute for Social and Political Opinion Research (ISPO) / Centre for Sociological Research \\ (CeSO), University of Leuven
}

\section{Accepted for publication in Social Problems}




\title{
Differentiated threat and the genesis of prejudice. Group-specific antecedents of homonegativity, Islamophobia, anti-Semitism and anti-immigrant attitudes
}

\begin{abstract}
In this article we argue that an exclusive focus on the generalized aspect of prejudice limits understanding of the structure and genesis of prejudice towards particular out-groups. In order to conceptualize the specific nature of particular prejudices, we propose the differentiated threat approach. This framework postulates that different out-groups challenge diverse realistic and symbolic interests, and that these out-group specific threats affect various socio-economic strata and cultural groups differentially.

The differentiated threat approach is applied to analyse majority-group Belgians' attitudes towards immigrants, Muslims, Jews and homosexuals. The results show that a common denominator of prejudice can be distinguished, but that the prejudices towards the various out-groups contain substantively relevant unique components that are influenced by socio-demographic and attitudinal predictors in diverging ways. Gender traditionalism is found to reinforce homonegativity and temper Islamophobia at the same time. Feelings of relative deprivation are more strongly related to Islamophobia than to other forms of prejudice, and are unrelated to homonegativity. Religious involvement plays a more decisive role in the formation of antiSemitism and homonegativity than it does in the other forms of prejudice. Anti-immigration attitudes show a class gradient that is absent in attitudes towards other out-groups.

Our results evidence that the concrete realization of attitudes towards a specific out-group cannot be understood without paying attention to structural and contextual factors, such as social positions, the nature of inter-group relations, power balances and elite discourses.
\end{abstract}

Key words: generalized prejudice, anti-Semitism, homonegativity, Islamophobia, differentiated threat approach 


\section{Differentiated threat and the genesis of prejudice. Group-specific antecedents of homonegativity, Islamophobia, anti-Semitism and anti-immigrant attitudes}

\section{Introduction}

Already in the early days of research on inter-group relations, scholars have put forward the idea that negative feelings tend to generalize across various out-groups (Allport 1958; Adorno et al. 1950). Numerous studies have evidenced how this so-called 'generalized prejudice' (Akrami, Ekehammar and Bergh 2011; Bäckström and Björklund 2007; Duckitt and Sibley 2007) or 'group-focused enmity' (Zick et al. 2008) is related to personality traits and ideological orientations such as right-wing authoritarianism and social dominance orientation (Asbrock, Sibley and Duckitt 2010; Ekehammar et al. 2004).

The discovery of a common denominator in negative attitudes towards various out-groups has contributed to our knowledge of inter-group relations. In this article, however, we argue that the exclusive focus on the common denominator of prejudices tends to obscure the particular causes of prejudice towards specific out-groups. Our argument is that - while the formation of general negative out-group attitudes takes place along more or less universal social-psychological mechanisms - the concrete realization of attitudes towards particular out-groups is crucially dependent on both structural and contextual factors (see Akrami et al. 2011). Social positions of the individuals and their sense of group position, inter-group relations characterized by differential social contact, socio-economic competition and power balances, as well as available media and elite discourses might explain why prejudice is triggered toward one out-group but not towards others (Hagendoorn 1995). Although this is acknowledged in the literature (Agnew, Thompson 
and Gaines 2000; Ray and Lovejoy 1986; Zick et al. 2008), a systematic theoretical elaboration and empirical test of the specificity of prejudices towards various out-groups is still lacking.

In this article, we develop a theoretical framework - the differentiated threat approach - that conceptualizes how different out-groups may be prejudiced against for different reasons by different strata of the in-group. Subsequently, we provide an empirical application of this approach by engaging with two generalizability questions: (1) To what extent do negative attitudes generalize across different out-groups? Can we ascertain generalized prejudice or do individuals hold differentiated views regarding various social out-groups? (2) Can a single, general causal model explain negative attitudes towards various out-groups or are specific prejudices triggered by particular sets of predictors, as the differentiated threat approach predicts? These questions are answered by articulating them in the concrete intergroup context of Belgium, where attitudes of Belgian majority-group members towards four out-groups, namely immigrants, Muslims, Jews and sexual minorities are scrutinized.

\section{Theory and hypotheses}

\subsection{Generalized prejudice: Personality and the common denominator of prejudices}

A dominant paradigm in social-psychological studies of inter-group relations stresses that the inclination to hold prejudices generalizes across out-groups. This idea of 'generalized prejudice' was already present in Allport's seminal study, where he noted that "people who reject one outgroup will tend to reject other out-groups. If a person is anti-Jewish, he is likely to be antiCatholic, anti-Negro, anti any out-group" (Allport 1958: 66). More recently, Zick et al. (2008) introduced the concept of 'group-focused enmity' (GFE) to refer to a generalized devaluation of out-groups with an ideology of inequality as its common core. Hostile attitudes toward different 
out-groups, who are considered to be unequal, socially threatening and/or culturally deviant, are understood as the components of a single syndrome, namely GFE (see also Zick et al. 2008). Over the years, numerous studies have accumulated empirical evidence for this hypothesis. Prejudices towards very diverse social groups - including various ethnic and religious groups, but also women, sexual minorities, elderly people, disabled persons and homeless people — are indeed found to correlate very strongly (Altemeyer 1998; Agnew et al. 2000; Bierly 1985; Bratt 2005; Ekehammar et al. 2004; Zick et al. 2008).

The GFE approach not only implies a stable structure of interrelated prejudices, but also argues that the various components are triggered by a single set of antecedents. Explanations why individuals are so consistent in their acceptance or rejection of various out-groups are often sought in person-based variables such as personality traits, ideological dispositions and cognitive styles (Hodson and Dhont, 2015). Adorno and his colleagues (1950), for example, maintained that general out-group negativity is rooted in an authoritarian personality structure. Building on this theoretical claim, contemporary scholars argue that individuals with high levels of right-wing authoritarianism tend to reject out-groups they consider as a threat to the social-cultural order namely in-group values, norms, stability and security. Individuals with strong social dominance orientations, on the other hand, are more inclined to devalue groups of perceived lower social status (Duckitt and Sibley 2007). Similarly, generalized prejudice has been linked to Big Five personality traits like agreeableness and openness to experience (Ekehammar et al. 2004).

Personality is not the only factor put forward to explain generalized prejudice, however. Low educated, unemployed and non-manual workers, men and elderly persons are generally more prone to hostility towards out-groups (Altemeyer 1998; Zick et al. 2011; Schiefer 2013). Also 
religious involvement is claimed to play a — albeit somewhat paradoxical — role in the genesis of generalized prejudice. Christian fundamentalism is positively related to feelings of GFE (Koopmans 2015), but other measures of Christian religiosity, such as church attendance, are only weakly associated with general out-group hostility (Altemeyer and Hunsberger, 1992).

In summary, the generalized prejudice approach (1) focuses primarily on the common component of generalized prejudice rather than on the particularity of the specific components; and (2) seeks the origins of generalized prejudice in characteristics of the individual, such as cognitive capacities, personality structures and socio-demographics, rather than in the social context of specific intergroup relations and features of the target group.

\subsection{The differentiated threat approach: Social context and the out-group specificity of prejudice}

An exclusive focus on the generalized character of prejudice limits our understanding of prejudice. Which out-groups become subject to derogation and negative imagery depends crucially on "the options a specific society offers" (Zick et al. 2008: 367). Although early (Allport 1958) and more recent (Fiske, Cuddy, Glick and Xu 2002) social-psychological studies have recognised the importance of situational factors for understanding prejudice (but see also Choma and Hodson 2008), several sociological theories stressed the importance of more insight in the structural and contextual factors of prejudice — including patterns of social contact and competition, economic and power relations as well as media and elite discourses positions — in order to understand why negative attitudes towards specific (and not all) out-groups are triggered (see e.g. Agnew et al. 2000; Akrami et al. 2011; Ray and Lovejoy 1986). 
Blumer's (1958: 3) concept of 'sense of group position' explicitly stresses the paramount importance of the concrete contexts and social structures in which intergroup relations are shaped: "[race] prejudice exists basically in a sense of group position rather than in a set of feelings which members of one racial group have toward the members of another racial group. This different way of viewing race prejudice shifts study and analysis from a preoccupation with feelings as lodged in individuals to a concern with the relationship of [racial] groups." This is to say, prejudice is a way to describe, justify, and understand one's own structural and group position in relation to that of out-group members. The development of prejudices, according to this logic, is fundamentally a social and collective process originating from dominant group members' perception that their proprietary claims over certain resources and privileges as well as their shared beliefs and social hierarchies are being challenged by a subordinate group. In similar vein, scholars like Bobo (Bobo and Hutchings, 1996; Bobo, 1999) and Bourdieu $(1985 ; 1990)$ characterize social space as a universe of ongoing struggle between individuals and groups, making clear that it is meaningless to study particular expressions of prejudice without reference to the specific context of relative group positions and intergroup struggles within different social fields. Such a relational perspective posits prejudices as structured by the in-group's relative positioning vis-à-vis outgroups in the power configuration and their ability to mobilize their capital (social, cultural, economic and/or symbolic) to sustain or improve status (Bourdieu, 1984; Bobo, 1999). As such, the particular characteristics of the relations between two groups facilitate certain prejudices and inhibit others.

Similarly, pioneers of Group Conflict Theory (GCT), such as Key (1949) and Blalock (1967) observed that anti-Black prejudice and discrimination were more prevalent in US regions where blacks made up considerable proportions of the resident population. This led to the idea that 
prejudices towards out-groups are essentially rooted in the perception that they threaten prerogatives of the own social group (Meuleman, Davidov \& Billiet 2009). In this logic, prejudice is seen as a defensive reaction to a sense of threat caused by conflicts between two or more social groups. This approach emphasizes the role of social comparisons - essentially not egoistic, but fraternal or group relative deprivation - to explain the genesis of prejudice. Individuals who perceive that their in-group is worse off or disadvantaged in comparison to a relevant out-group are more likely to express prejudice toward that group (Merton 1957; Runciman 1966).

In order to investigate the out-group specific antecedents of prejudice, the general idea that outgroup threats cause prejudice among the dominant population needs to be qualified in two ways — we call this the differentiated threat approach: (1) The type of perceived threat is idiosyncratic to specific intergroup relations; and (2) Out-group threats do not affect a society as a whole, but disproportionally affect specific socio-economic strata and cultural segments of the in-group. Consequently, the differentiated threat approach — as a theoretical lens — can only be understood and articulated with explicit reference to the specific social contexts.

The first component of the differentiated threat approach acknowledges that the nature of the perceived conflict/threat can be very diverse. Out-groups can challenge the collective interest, identity and power status of the in-group, resulting in different types of threat (Riek, Mania and Gaertner 2006). On the one hand, realistic or socio-economic threat is induced by the (subjective) experience of relative deprivation, caused by competition for material goods such as well-paid jobs, affordable housing, or resources of the welfare state (Olzak 1992). Symbolic or cultural threat, on the other hand, originates in inter-group conflict over the established social order, cultural traditions, and shared beliefs, norms and values (Stephan et al. 1998). Importantly, 
distinct out-groups can be perceived either as a realistic threat, a symbolic threat or a combination of both (Hjerm and Nagayoshi 2011). Based on the nature of perceived threat (realistic vs. symbolic) posed by out-groups, various types of 'Others' can be distinguished - see Figure 1:

(1) Deviant groups (low realistic threat, high symbolic threat): non-subordinated out-groups who are violating the social norms and threatening the established social-cultural order, and societal stability. These groups are perceived as socially/culturally deviant, but not struggling for collective resources and not necessarily of lower social status (e.g. LGBT, Ku Klux Klan members, or Atheists in the US);

(2) Competing groups (high realistic threat, low symbolic threat): socially subordinated outgroups with low status and power who compete actively for scarce resources and challenge social inequalities, but not culturally deviant. These groups can be classified as disadvantaged normconformists since they are not challenging the values of the in-group, but the distribution of collective resources (e.g. unemployed or homeless people); and

(3) Dissident groups (high realistic threat, high symbolic threat): out-groups seen as competing with but also threatening the in-group since they tend to struggle actively for scarce resources and are challenging the in-group's values and norms at the same time. These groups could be described as usurpers trying to seize status and power by claiming scarce resources and shifting established cultural order (e.g. immigrants).

This categorization of groups bears resemblance with Schneider and Ingram's (1993) theory on the social construction of target groups that distinguishes groups on the basis of their power resources and the valence of the social constructions (positive vs. negative).

In line with the dual-process motivational model (Duckitt 2006) and the Stereotype Content Model (Fiske et al. 2002), we argue that different types of out-groups may be prejudiced against 
for distinct reasons, according to different group-specific mechanisms such as the nature of the perceived threat and the content of ascribed stereotypes. Prejudices against out-groups that are symbolically threatening (e.g. deviant groups) are predominantly driven by authoritarian dispositions. Feelings of relative deprivation, on the other hand, are expected to induce prejudices towards socially subordinate groups competing for scarce resources (e.g. competing groups) (Asbrock, Sibley and Duckitt 2010). Similarly, Fiske et al. (2002) show that prejudices cluster along two dimensions, namely 'perceived competence' defined by the relative socioeconomic status of groups (low versus high status) and 'perceived warmth' defined by the type of interdependence between groups (competitive versus cooperative). As a consequence, groups that are perceived to be similar on stereotype content are targeted for similar reasons.

\section{[Figure 1 about here]}

The second component of the differentiated threat approach is its focus on the social stratification and cultural diversity of the dominant society. The dominant group cannot be reduced to a homogenous bloc, but is instead segmented into different socio-economic classes (with distinct risks and resources) and cultural groups (with distinct value patterns and ideological dispositions). Therefore, intergroup competition for realistic and symbolic goods does not affect all groups in society to the same degree. Realistic threats emanating from specific out-groups will only affect certain socio-economic segments of the dominant group, while symbolic threats posed by distinct out-groups will only appeal to some cultural sections of dominant society. Conversely, prejudiced attitudes are not necessarily directed towards all possible out-groups, but are rather focused on those out-groups that are socially constructed as a challenge to realistic and/or symbolic interests (Schneider and Ingram 1993). 
The differentiated threat approach can thus be translated into a two general propositions: (1) Socio-economic segment A of the dominant society will develop prejudice towards out-group B if out-group B threatens the realistic interests of segment A; (2) Cultural segment C of the dominant society will develop prejudice towards out-group D if out-group D threatens the symbolic interests of segment C. Below, these two propositions are translated into testable hypotheses regarding prejudices towards four out-groups in Belgium.

\subsection{Contextualizing specific prejudices : the case of Belgium}

The quintessence of the differentiated threat approach is that prejudices cannot be understood in abstracto, but instead they need to be situated in social space (cf. Bourdieu, 1985), i.e. the specific structural positions, competitive contexts and cultural-discursive contexts in which intergroup relations are embedded. The general propositions of the differentiated threat approach cannot be tested directly but provide an operational lens by which prejudice can be studied in a particular social space. This contribution illustrates how this can be done by applying the theoretical framework of the differentiated threat approach to the particular context of Belgium. We focus on prejudices towards four out-groups that figure prominently in current debates in Belgium: immigrants, Muslims, homosexuals, and Jews. Below, we contextualize the societal positions of the four groups and derive hypotheses on the group-specific antecedents of prejudice that indirectly allow us to assess the basic premises of the differentiated threat approach.

In the Belgian context the notion of 'immigrants' is predominantly associated with Turkish and Moroccan communities that have their roots in the post-war labor migration. The popular use of the term immigrants often also includes the $2^{\text {nd }}$ and $3^{\text {rd }}$ generation descendants of these labor migrants. Persons of Turkish and Moroccan descent generally occupy disadvantaged socio- 
economical positions and are often perceived as a threat for low-skilled jobs and social welfare provisions of the native Belgians (Abts \& Kochuyt 2013). As a culturally visible and distinct outgroup, immigrants of Turkish and Moroccan origin are perceived as a threat to the established social-cultural order as well (Swyngedouw 1995). In this sense, this target group can be described as 'dissident': both competing with low-skilled natives for resources and status, and threatening the in-group's norms and values.

Although many persons of Turkish and Moroccan descent are Muslim, it is of crucial importance to distinguish anti-immigration attitudes from a second form of prejudice, namely Islamophobia. Islamophobia refers to indiscriminate negative attitudes or hostility toward Islam and Muslims as a religious community (Bleich 2011). In Western Europe, since 9/11 the supposed historical incompatibility of European and Islamic values is central to the rise of Islamophobia (Strabac and Listhaug 2008). Anti-Islam discourse depicts Islam as a monolithic, inherently violent and uniquely sexist religion, whose followers are seen as the ultimate cultural 'Other' that will never be able to cope with democratic and liberal values of Western society (Kumar 2012; Taras 2012). Islam as a denomination and Muslims as a religious-cultural group are in the eyes of prejudiced individuals a cultural rather than an economic threat, and are therefore considered as a 'deviant' group.

Third, homonegativity refers to the degree of prejudicial biases towards gay, lesbian, bisexual and transsexual (LGBT) people (Hudson and Ricketts 1980). Although Belgium is known as a frontrunner in terms of LGBT rights and the social climate has become more positive in the last decade (Aerts et al. 2014), homonegativity is still present in Belgian society. The core of homonegative discourse is that homosexuality poses a threat to the social-cultural order: 
Homosexuals are a 'deviant group', threatening the Christian value system, violating traditional morality and challenging conventional gender role patterns.

Fourth, anti-Semitism refers not to hostility toward Israel, but to the cultivation of resentments against an imagined and generalized 'collective Jew' who is a cultural Other doing no effort to assimilate, and is at the same time a powerful Other having strong grip on the economy competing with domestic actors - thus 'dissident' (Schiffer and Wagner 2011; Meer 2013). Yet, the nature of dissidence ascribed to Jews is quite specific. Most dissident groups are precisely blamed for not contributing enough to the economy and being in competition with low-skilled natives for scarce resources (e.g. the Turkish and Moroccan communities). The prototypical ultra-orthodox Haredi Jews (who are strongly concentrated in Antwerp and dominate its diamond industry) are on the contrary blamed for trying to control domestic economy and world finances. As such, whereas immigrant communities are dissidents of low social status, Jews are imagined as dissidents of high status (Fiske et al. 2002).

Note that our selection of out-groups does not cover all theoretically possible types of Others (see Figure 1) since our study comprises two deviant (homosexuals and Muslims) and two dissident (immigrants and Jews) groups. Although it does not include an example of competing Others, our study contains sufficient variety in intergroup contexts to illustrate the differentiated threat approach empirically.

This contextualization, combined with the propositions of the differentiated threat approach, leads to expect that the different forms of prejudice are triggered — at least partially — by groupspecific antecedents. The first proposition of the differentiated threat approach relates to the axis 
of realistic threat and stipulates that socio-economic segments of dominant society will develop prejudice towards out-groups that threaten their specific realistic interests. Since immigrants as well as Jews are seen as an economic threat — albeit each in their own way —, especially persons with strong feelings of relative deprivation are expected to develop prejudice towards these groups. We anticipate relative deprivation to be a more relevant antecedent for anti-immigrant attitudes and anti-Semitism than for the other forms of prejudice like homonegativity or Islamophobia, which are predominantly rooted in perceptions of cultural threat. However, the socio-economic status and hence nature of the economic competition posed by immigrants and Jews is radically different. As a result of the specific form of ethno-stratification in Belgium, especially low-skilled natives experience persons of Turkish and Moroccan descent as competitors for scarce economic goods (especially jobs, housing and welfare provisions). As a result, antiimmigration attitudes are expected to crystallize along class lines, with low-skilled manual workers and the unemployed showing higher levels of anti-immigrant attitudes (Kunovich 2004). In the case of anti-Semitism, such class gradient is not expected.

The second proposition of the differentiated threat approach relates to the symbolic axis, and states that the dominant cultural group will develop prejudice towards out-groups that threatens their specific symbolic interests. Islamophobia and homonegativity are both embedded in cultural rather than in economic threat perceptions. Muslims as well as sexual minorities are perceived as a threat to social order and dominant value schemes, but the specific sets of values these outgroups challenge are far from identical. As a result, Islamophobia and homonegativity are triggered according to group-specific mechanisms, albeit in quite different social groups characterized by different value patterns. The relationship between traditional gender role attitudes (Thornton, Alwin and Camburn 1983) and the formation of prejudices exemplifies this 
crucial point perfectly. Regarding sexual minorities, one of the most persistent stereotypes about homosexuality relates to the violation of (patriarchal) gender norms (Aerts et al. 2014). Consequently, homonegativity is expected to be more prevalent among individuals identifying strongly with traditional gender roles. Similarly, males generally hold stronger homonegative beliefs than women (Herek 1988). This gender dimension of homonegativity is not just an effect of sex per se, but is closely related to the gender role expectations within society, especially the hegemonic (traditional) conceptions of masculinity (Connell 2005; Plummer 1999). Islamophobia is linked to threats to gender role expectations as well, but with different (if not opposite) underlying values and mechanisms. The idea that Islam is an inherently sexist religion is one of the constituting myths of Islamophobic discourse (Kumar 2012). Because the critique that Islam oppresses women resonates among persons who endorse gender equality, negative attitudes against Muslims are especially strong among persons rejecting traditional gender norms, which imply male domination and patriarchy. The paradoxical situation that gender traditionalism reinforces homonegativity and at the same time tempers Islamophobia is also apparent from discourse of political elites. Extreme-right wing political actors regularly mobilize the frame of the 'homonegative Muslim community' in order to exhort anti-Islam sentiments (Bracke 2012).

Besides gender equality, Islam is also perceived as a threat for certain value sets - such as separation of church and state, individual rights/freedom, democracy and tolerance - that are strongly endorsed by the higher educated. In the eyes of this presumably tolerant group, Islam skepticism becomes legitimate as a defense of tolerance, liberal democracy and Enlightenment (Bilsky 2009; Spruyt and Elchardus 2012). In other words, the 'Muslim Other' is transformed into a 'suitable enemy,' i.e. a more legitimate object of prejudice (Fekete 2009). Hence, highly 
educated citizens might be more likely to hold negative attitudes towards Muslims than towards other out-groups, like immigrants, Jews or homosexuals.

The impact of religiosity on group-specific prejudices can be understood from the framework of cultural threats, but is highly complex. Allport (1958: 444) already asserted that religion can both make and unmake prejudice. Although most religions preach tolerance toward out-groups, they permit some forms of prejudice against people who are perceived to violate the religion's value system. A literature review supports the distinction between proscribed prejudices (race/ethnicity) and permitted prejudices (homosexuality) (Hunsberger and Jackson 2005). Following the Catholic teaching identifying homosexuality as opposing religious morality and value system, the Church enables prejudice against LGBT, as it is consistent with religious beliefs (Whitley 2009). Similarly, the portrayal of the role of Jews in the crucifixion of Jesus Christ or, more generally, their threat to Christianity might promote anti-Semitism among church-involved Christians (Pargament et al. 2007).

\subsection{Hypotheses}

Based on the generalized prejudice and differentiated threat approaches, we can derive two sets of hypotheses regarding the commonality $(\mathrm{H} 1-\mathrm{H} 9)$ and specificities $(\mathrm{H} 10-\mathrm{H} 20)$ of prejudice towards immigrants, homosexuals, Muslims and Jews (see Table 1 for a summary). According to socialpsychological theory, a strong common denominator — namely GFE or generalized prejudice can be distinguished in prejudices towards the four out-groups (H1). The respective prejudices are anticipated to be shaped by the same antecedents. Higher levels of generalized prejudice are expected among men (H2), elderly persons (H3), lower educated individuals (H4), lower social 
classes (H5) and religious persons (H6). Authoritarianism (H7), feelings of relative deprivation (H8) and gender traditionalism (H9) are hypothesized to reinforce generalized prejudice.

The differentiated threat approach, on the other hand, predicts that prejudices towards immigrants, homosexuals, Muslims and Jews cannot be reduced completely to a single common denominator and expects considerable particularities for the different prejudices (H10). Furthermore, the four prejudices are assumed to originate along specific mechanisms. Note that the hypotheses regarding group-specific antecedents are formulated in terms of deviations from the general pattern (i.e. the explanatory model for GFE).

- Homonegativity: Gender is expected to affect homonegativity even more strongly than GFE. While men are more prejudiced than women towards out-groups in general (see $\mathrm{H} 2$ ), the gender gap is expected to be more outspoken when homonegativity is concerned (H11). Similarly, religious involvement is anticipated to have a stronger impact on homonegativity (H12), while feelings of relative deprivation are assumed to be less relevant when explaining negative attitudes towards LGBT people (H13). Homonegativity is expected to be more outspoken among gender traditionalists (H14).

- Anti-immigrant attitudes: Belonging to the lower social classes (H15) and relative deprivation (H16) are expected to stimulate anti-immigrant sentiments more strongly than generalized prejudice.

- Islamophobia: Whereas a low educational level is supposed to be a strong predictor of general prejudice (see H4), we expect a less outspoken educational gradient for Islamophobia (H17). Furthermore, gender traditionalists are hypothesized to show lower levels of Islamophobia (H18). 
- Anti-Semitism: religious involvement (H19) as well as relative deprivation (H20) are assumed to have a stronger positive effect/relation with on anti-Semitism than on GFE.

\section{[Table 1 about here]}

Importantly, these hypotheses illustrate that generalized prejudice and differentiated threat approaches are not mutually exclusive, but rather complement each other. Whereas the idea of generalized prejudice provides the general underlying mechanism through which prejudices originate, the differentiated threat approach provide more specific insights in which out-groups are targeted by which socio-economic and cultural categories.

\section{Data and Methods}

\subsection{Dataset}

To test the hypotheses, the Belgian data collection for the $4^{\text {th }}$ round of the European Values Study is used. In 2009, a two-stage probability sample of the Belgian population older than 18 years were approached by means of a computer assisted personal interview (CAPI). The realized sample size is 1509 (response rate: 50.0\%). Upon completion of the interview, participants were asked to fill out a drop-off questionnaire and send it back by mail. $75.2 \%$ of the participants in the CAPI (i.e. 1136 respondents) returned a completed drop-off. Non-response analysis shows that certain groups (such as persons aged 40 to 54 and those with a tertiary education) are overrepresented in the realized sample, while others (persons without secondary education, individuals younger than 25 and those over 70) are underrepresented. To remediate this imbalance, we apply poststratification weights correcting for the joint distribution of gender, age and education. Because this study focuses on the structure of prejudices among majority-group members, respondents of 
immigrant background (operationalized as not having Belgian nationality or being born abroad) are excluded from the analysis, leading to an effective sample size of 1007.

\subsection{Indicators}

Measures of prejudice - Each form of prejudice is measured by 4 to 6 Likert-items. These items were included in the drop-off questionnaire with a maximal spread in order to minimize memory effects and contamination. Homonegativity is measured by means of statements referring to the (ab)normality of homosexuality (q7_1 \& q7_5), homosexuality as a normative threat (q7_2), openness of homosexual identities (q7_3) and non-discrimination of homosexuals (q7_4). Antiimmigrant attitudes are operationalized by items regarding to the trustworthiness of immigrants (q8_1), social security threat posed by immigrants (q8_2) and the impact of immigration on cultural life (q8_3 \& q8_4). The introductory text to this battery states that the term immigrants refers in the first place to persons of Turkish of Moroccan origin living in Belgium. Four statements referring to the presumed influence (q15_2), self-complacency (q15_3), trustworthiness (q15_4) and greediness (q15_5) of Jewish persons indicate Anti-Semitism. Finally, Islamophobia is measured by means of items on the role of women in Islam (q24_2), the presumed violent nature of Islam (q24_4) and Islam as a geopolitical (q24_3) or cultural (q24_5) threat to Western society. The scales are partially balanced. Besides statements expressing a negative attitude, also positively worded items are included. To answer these statements, respondents were offered 5-point scales, ranging from 'agree completely' (1) to 'disagree completely' (5). Validity, reliability and dimensionality of the items were tested and confirmed by means of Confirmatory Factor Analysis (CFA; see Appendix 1). 
Explanatory variables - Various indicators of social-structural position are included, namely gender,,age (in years) and educational level (up to lower secondary degree - higher secondary degree - tertiary degree). In the operationalization of religious involvement, we make a distinction between Christians (mostly Catholics) who attend religious services on a regular basis (i.e. at least once per month); persons who consider themselves as Christians but who do not or only occasionally attend services, and non-believers and atheists. Employment status is based on the Erikson-Goldthorpe-Portocarero (EGP; Ganzeboom and Treiman 1996) social class scheme, and distinguishes between (1) Service Class I and the self-employed; (2) Non-manual workers (i.e. Service Class II and routine non-manuals); (3) Manual workers (skilled and unskilled); (4) Those who never worked (and for which the EGP category can consequently not be determined).

A second set of predictors concerns three attitudinal dimensions, each operationalized by means of multiple indicators (5-point agree-disagree statements). Authoritarianism is measured by means of three items on the importance of obedience and respect (q12_4), strict laws (q12_5) and punishment of immoral persons (q12_3). Three items (q30_1-q30_3) referring to the feeling of being disadvantaged as a group by government and institutions indicate group relative deprivation. Finally, gender traditionalism is measured by means of items regarding genderstereotypical education for boys and girls (q14_1 \& q14_2) and the gender roles on the labour market (q14_3 \& q14_4). CFA showed that these items are sufficiently valid and reliable measurements for the intended concepts (see Appendix 2).

\subsection{Statistical modelling}

The statistical analysis is carried out in two major steps. First, in order to study how strong the common and group-specific components of prejudice are, we estimate a second-order 
confirmatory factor model (see also: Bratt 2005; Zick et al. 2008). The point of departure of this approach is that a respondent's response to a statement regarding a specific out-group reflects three components: (1) second-order factor GFE, i.e. the common component of prejudices; (2) group-specific prejudice, i.e. prejudice towards the out-group explicitly mentioned in the items; and (3) random measurement-error at the item-level. ${ }^{\mathrm{i}}$ The model thus specifies a so-called secondorder factor (i.e. GFE) that captures the common variance of the first-order factors (i.e. the groupspecific prejudices) - see Figure 2.

Second, in order to study whether the roots of prejudice are common or group-specific (the second generalizability question), structural and attitudinal variables are added to the second-order CFA model (see Figure 3). This model captures the similarity of antecedents by estimating effects of the predictors on the second-order factor GFE (H2-H9). Group-specific explanations (H11-H20) are incorporated by allowing direct effects from the predictors on the various forms of prejudice (the first-order factors). These direct effects indicate deviations from the common explanatory model, i.e. that the impact of the respective predictor on the specific prejudice is different from that on the GFE factor. For reasons of parsimony, only effects from the predictors to the specific prejudices that lead to a significant improvement are introduced in the final model.

All reported models are estimated using Mplus version 7.1. The ordered-categorical nature of the indicators is taken into account by using the robust weighted least squares estimator (WLSMV). All reported parameters below are standardized, apart from the effects of the dummy variables, which are semi-standardized. As a result, the effects of dummy variables refer to the difference with the reference category in terms of standard deviations on the dependent variable. 


\section{Results}

\subsection{The common denominator of prejudices: A second-order factor model}

In order to analyse to what extent group-specific prejudices share a common denominator, we estimate a model with four first-order factors (anti-immigrant attitudes, homonegativity, Islamophobia and anti-Semitism) loading on a second-order factor, capturing the communality of prejudices or GFE (see Figure 2). The anti-immigrant factor is allowed to correlate with Islamophobia, since the immigrant group referred to - people of Turkish and Moroccan origin is predominantly Muslim. The first-order factor loadings are quite high (mostly $>.60$; many $>.80$ ), indicating that items are sufficiently valid and reliable measurements. This second-order factor model has an acceptable model fit (see Modell in Table 2): The Root Mean Squared Error of Approximation (RMSEA) equals 0.065 , and both the Comparative Fit Index (CFI; 0.968) and Tucker-Lewis Index (TLI; 0.962) are sufficiently close to 1 . The second-order factor model has a substantially better fit than a model in which the four specific prejudices are not related to each other (implying that there is no communality; see Model2 in Table 2) or a model in which all items load on a single first-order factor (meaning that prejudice has no group-specific components; see Model3 in Table 2). This confirms our hypotheses: overlap indeed exists between the specific prejudices (H1), but at the same time they contain specific components and can therefore not be reduced to a single GFE dimension (H10).

[Table 2 \& Figure 2 about here]

The second-order factor loadings contain information on the relative importance of the specific and common components. All factor loadings are high ( $0.54,0.53,0.86$ and 0.60 respectively), expressing that the specific prejudices are strongly influenced by the common GFE factor. Interestingly, the loading for anti-immigrant attitudes is substantially stronger than for the other 
three forms of prejudice. A general inclination to prejudice informs attitudes towards all outgroups, but it does even more so for anti-immigrant attitudes. The factor loading approaches 1, indicating that it becomes very hard to distinguish between GFE and anti-immigrant attitudes. In the Belgian public opinion the category 'immigrant' is the master template into which processes of the formation of generalized prejudice are projected. Immigrants, especially of Turkish and Moroccan descent, have become the Belgian archetypical object of Othering.

Based on the second-order factor loadings, the common (communalities) and specific (uniqueness) components of the four forms of prejudice can be calculated. The communalities represent the proportion of variance that the forms of prejudice share with the common GFE factor. Table 3 shows that the different prejudices have substantial unique components. Homonegativity, Anti-Semitism and Islamophobia share roughly one third of their variance with GFE, while two thirds of the variance is out-group specific. The overlap between anti-immigration attitudes and GFE is considerably larger (namely 74\%). But even in this case, a non-negligible portion of variation $(26 \%)$ is specific for the out-group referred to. By consequence, an exclusive focus on this communality - that constitutes only the smaller share of the variance - leads by definition to a limited understanding of the genesis of prejudices.

[Table 3 about here]

\subsection{Common or differential antecedents: A full Structural Equation Model}

To study whether the different antecedents precede the specific forms of prejudice, structural and attitudinal predictors are added to the second-order factor model (see Figure 3). Table 4 displays the direct effects of the predictors on GFE (showing the common impact of the antecedents on prejudice in general) as well as the direct effects on the four specific prejudice-components (i.e. 
the deviations from the general pattern). Sometimes, these direct effects can be misleading as they represent impacts controlling for all other predictors (also those further in the causal chain). Therefore, Table 5 additionally displays the total effects of the predictors on the prejudices. These total effects are the sum of the direct effects shown in Table 4 and the indirect effects that run through the mediating variables. Detailed insight in the explanatory model requires information on both effects. While the direct effects are especially useful to uncover differential impacts of predictors, the total effects provide insight in the general patterns in the data.

[Figure 3, Table 4 \& Table 5 about here]

We start the interpretation with the common impact of antecedents, i.e. the effects on GFE. Each of the three attitudinal variables is significantly related to GFE (see Table 4). As hypothesized, persons with feelings of relative deprivation (H8) and an authoritarian disposition (H7) tend to hold more prejudiced views in general. Especially authoritarianism is strongly linked to GFE: An increase of one standard deviation on the authoritarianism-scale goes hand in hand with an increase of 0.594 standard deviations of the GFE-score. Also the endorsement of traditional gender roles turns out to be positively linked to GFE, although the impact is considerably weaker (0.130). Of all structural variables, only education and age are significantly related to GFE. As expected, education has a strong tempering effect on generalized prejudice (H4). Looking at the total effects (Table 5), those with a degree from tertiary education score 0.682 standard deviations lower on GFE than persons with a lower secondary degree (i.e. the reference category). Also between individuals with a higher secondary and a lower secondary degree a significant difference (of -0.221) is found. Education has no significant direct effect on GFE, however (see Table 4), indicating that the educational effect is fully mediated by the three attitudinal variables. The fact that the higher educated report less prejudice is completely accounted for by the fact that this 
group has a less authoritarian worldview, feels less deprived and is more critical of traditional gender roles. In contrast to $\mathrm{H} 3$, age does not have a significant overall impact on GFE. When the attitudinal characteristics of the older cohorts are controlled for, we detect a negative net age effect (-0.155; see Table 4). Gender (H2), social class (H5) and religious involvement (H6) are not significantly related to GFE, which contradicts our hypotheses as well. Taken together, the structural and attitudinal predictors explain almost 60 per cent of the total variance of GFE.

The primary purpose of this analysis, however, is to find out whether certain predictors have group-specific effects that deviate from this general pattern. The fact that several predictors have a direct effect on the first-order prejudices indicates that such differential effects are indeed present. It was already mentioned that relative deprivation had a moderate, positive effect on GFE. Direct effects of relative deprivation on homonegativity and Islamophobia, however, evidence that attitudes towards these two specific out-groups deviate from this general effect of relative deprivation. In case of homonegativity, the direct effect is negative (-0.158 in Table 4). Compared to other forms of prejudice, the impact of relative deprivation on homonegativity is significantly weaker, which is exactly what was anticipated (H13). The total effects in Table 5 show that, overall, relative deprivation is not significantly related to homonegativity. Clearly, the perception of being deprived can translate into prejudiced attitudes, but not towards homosexuals. On the contrary, a positive direct effect of relative deprivation on Islamophobia (0.109) illustrates that relative deprivation instigates anti-Muslim sentiments even more that it does so for prejudice towards out-groups.

Gender traditionalism has a differentiated impact on homonegativity and Islamophobia. Traditional gender attitudes have a strong positive direct effect on homonegativity (0.364). While 
gender traditionalism has a quite modest positive impact on prejudice in general, attitudes towards homosexuals are much more clearly structured along gender role expectations, thereby confirming H14. Of all predictors of homonegativity, gender traditionalism has most explanatory power. For those adhering to traditional gender roles, homosexuality clearly presents a strong value threat. The situation is quite different in the case of Islamophobia: As expected (H18) traditional gender attitudes have a negative direct effect $(-0.207)$ that counteracts the overall prejudice-inducing effect of gender traditionalism completely. The total effect of gender traditionalism on Islamophobia is significantly negative. Thus, persons stressing the importance of gender traditionalism tend to be more prejudiced in general, but are found to score lower on Islamophobia. This is not surprising, given that the subordinate position of Muslim women is one of the constitutive myths of Islamophobia. As expected, the impact of authoritarianism, finally, is far less differentiated. For each of the specific forms of prejudice, authoritarianism is the single most important predictor, and no prejudice-specific effects are detected.

Differentiated effects are also found for several structural variables. While no significant gender differences exist regarding GFE, women do report less homophobic attitudes than men (direct effect: -0.169; see Table 4), which confirms H11. Also as expected, social class has a differential impact on anti-immigrant attitudes (H15). In terms of the direct effects, there is a significant gap in anti-immigrant attitudes between non-manual and manual workers. In the total effects it can be seen that anti-immigrant attitudes is the only form of prejudice that is structured among class lines: The higher service class/self-employed and the non-manual workers report significantly less anti-immigrant sentiments than the manual workers (who serve as reference category in this analysis). Also religious involvement has differential impacts on homonegativity (H12) and antiSemitism (H19). As expected, the gap between church-goers and marginal Christians is more 
outspoken regarding homonegativity and anti-Semitism than for other prejudices. This pattern illustrates the role of homosexuals and Jews as permitted targets of prejudice among churchinvolved Christians.

In addition to the hypothesized effects, we also find a small but significant group-specific impact of age. In the case of homonegativity and Islamophobia, age has a direct positive effect $(0.178$ and 0.183 respectively - see Table 4). The same pattern can also be seen in the total effects (Table 5): Homonegativity and Islamophobia are the only two forms of prejudice for which a significant age effect is found. Homosexuality and Islam are the only issues for which an opinion gap between younger and older cohorts is observed. Finally, the hypothesis regarding the specific effect of education on Islamophobia (H17) was not confirmed.

Although the hypotheses tested here do not provide a direct test of the differentiated threat approach, this analysis indirectly renders clear support for its basic propositions. Our results provide a differentiated and nuanced view on the predictors of various prejudices. Besides a set of common antecedents, such as authoritarianism and educational level, the four forms of prejudice have quite different relationships to several predictors in the model. Furthermore, the pattern of group-specific antecedents largely confirms the key idea that prejudices are embedded in the realistic and symbolic intergroup conflicts; Prejudices towards a particular out-group develop among specific socio-economic (or cultural) segments of society who see their realistic (or symbolic) interest threatened. For homonegativity, this point is most obvious: The impact of 5 out of 8 predictors deviates significantly from the general pattern, and homonegativity is consistently stronger among the elderly, males, churchgoers and gender traditionalists - i.e. groups experiencing homosexuality as a stronger threat for the moral order. Also for Islamophobia, 
several differential effects are found that, interestingly enough often go in to opposite direction as those for homonegativity. The fact that Islamophobia and homonegativity correlate positively (see section 4.1) does not exclude that both forms of prejudice have partially different social roots and are shaped by different processes. Anti-immigrant attitudes deviate least from the common explanatory model. This is hardly surprising, given the large overlap between anti-immigrant prejudice and GFE. The particularity of the antecedents prejudices is also evidenced by the sizeable differences in explanatory power of the predictors: The model explains $69.8 \%$ of the variation in anti-immigrant attitudes vs. $28.3 \%$ in the case of anti-Semitism.

\section{Conclusion}

In this article, we argue that an exclusive focus on the generalized aspect of prejudices limits our understanding of the structure and genesis of particular prejudices. The realization of attitudes towards specific out-groups is contingent on structural and contextual factors, such as social positions, the nature of inter-group relations, power balances and elite discourses. In order to conceptualize the out-group specific nature of prejudices, we develop a theoretical framework the differentiated threat approach - that hinges on two crucial principles. First, the model acknowledges that the interests that are challenged by out-groups are diverse (realistic vs. symbolic threats), and that various types of out-groups — deviant, competing and dissident — can be distinguished. Second, the differentiated threat approach stresses that societies are structurally and culturally stratified, and that perceived out-group threats are not equally distributed across society, but disproportionally affect specific socio-economic strata and cultural groups depending on the nature of conflict. As a result, individuals' prejudices are not necessarily directed towards all possible out-groups, but are instead focused on out-groups that are perceived to challenge the realistic and/or symbolic interests of the relevant reference group. 
Paramount to the differentiated threat approach is that out-group threats are embedded in intergroup relations and have to be interpreted within specific contexts. Hence, in-depth knowledge about the intergroup relations in particular settings are required. As such, the relevance of the differentiated threat approach was tested empirically by analysing the attitudes of Belgian majority-group members towards four out-groups, namely immigrants, Muslims, Jews and sexual minorities. Our study shows that, although a common denominator of generalized prejudice can be distinguished, negative attitudes towards the various out-groups contain substantively relevant unique components. The degree to which a specific prejudice is linked with GFE varies across out-groups. A very strong overlap exists between GFE and anti-immigration attitudes, which suggests that in Belgian public opinion, the category 'immigrant' is the master template into which processes of the formation of generalized prejudice are projected.

Our analysis furthermore reveals that certain factors - such as low education, feelings of relative deprivation and an authoritarian disposition - consistently contribute to generalized prejudice. But we also find that this general explanation model ignores that specific prejudices are partly triggered by particular sets of predictors. Clearly, there are particular reasons and motivations to be prejudiced idiosyncratic to the out-group. The differential impact of gender traditionalism on Islamophobia and homonegativity illustrates this point perfectly. Gender traditionalism is the strongest factor inducing homonegativity, but tends to reduce anti-Islam feelings at the same time. The reason for this paradoxical effect should be sought in the specific content of prejudices towards homosexuals and Muslims. One of the most persistent stereotypes about homosexuality relates to the violation of traditional gender norms (including heteronormativity and patriarchy), while the critique that Islam is an inherently sexist religion oppressing women is precisely one of 
the constitutive elements of Islamophobia. Homosexuals as well as Muslims are disliked because they are perceived as a threat to certain values. But the specific value sets concerned and segments of society that feel threated are fundamentally different.

Various other predictors where found to have an out-group specific impact that deviates from the explanation model for generalized prejudice. Feelings of relative deprivation, for example, are more strongly related to Islamophobia than to other forms of prejudice, and are unrelated to homonegative views. Religious involvement plays a more decisive role in the formation of antiSemitism and homonegativity than it does in the other forms of prejudice. And anti-immigration attitudes show a class gradient that is absent in attitudes towards other out-groups. Notably, the analyses showed that especially the origins of homonegativity deviated from those of GFE. As such, homonegativity can be considered as a rather 'exceptional' case of prejudice. Looking at the position of LGBT in the Belgian context, this is not hugely surprising as homosexuality — as opposed to immigration or the increasing visibility of Islam — is much rather accepted by public opinion and almost a non-issue in political discourse.

This finding once more stresses the necessity of a contextualized approach. The structure of prejudices and the classification of out-groups (into dissident, deviant and competing groups) are not a universal given, but vary across societies and could undergo modifications over time. Zick, Küpper and Hövermann (2011), for instance, found that sexism and homophobia were much less associated in Hungary and Poland, compared to more Western countries. Besides, prejudice towards certain out-groups might move away from the GFE component, while attitudes towards others might move into the centre or even become the pinnacle of prejudice. This is illustrated by the finding that, due to the increased marketization of Western societies, prejudices toward 
unprofitable groups (e.g. unemployed and homoless) are claiming a more prominent position in the structure of prejudice (Hövermann, Gross, Zick, and Messner, 2015).

Our results confirm various hypotheses that were derived from the differentiated threat approach, and as such illustrate the necessity of a contextualized approach. These findings do not invalidate the theory of generalized prejudice, however. The generalized prejudice and differentiated threat approaches complement each other in the understanding of prejudice and excluding one from the other would provide a distorded and one-sided picture. As such, future research examining the origins of prejudice should try to differentiate between the group-specific and generalized component of prejudice and emphazise the contextualisation of the group-specific component. Furthermore, as the differentiated threat approach critically highlights the importance of context, future research should evaluate its theoretical underpinnings in different social settings. Doing so, future research could include examples of 'competing' groups - a type of Others that was not included in our empirical analysis. However, it cannot be overemphasized that studies using the differenitated threat appraoch need to be mindful that the out-groups that were analyzed in this article might hold different social positions and evoke different types of threat in other societies (for example, immigrants as a predominantly economic threat in Italy vs. cultural threat in France; Bergamaschi 2013). Finally, although our approach has a strong focus on threat, it has shown that prejudice is not solely based on uncontrollable personality traits but largely depends on situational group membership and the search for a positive self-identity and personal/community security (Kinder and Kam 2010).. Hence, it can be easily be translated for the study of group identities, which is related to the study of prejudices. For example, the differentiated threat approach, and it focus on the position of groups vis-à-vis each other, can be used by social identity researchers interested in how the positionality of the different others to the in-group may invoke differenitated 
othering mechanisms. Alternitevly, social identity researchers can further expand our differenitated threat model, by adding the layer of social identitifiation to the inter-group positionality.

\section{References}

Abts, K., Kochuyt, T. (2013). De vreemde bedreiging van de verzorgingsstaat. Tijdschrift voor Sociologie, 34 (3-4), 227-249.

Adorno, Theodor W., Frenkel-Brunswick, Else, Levinson, Daniel K. and R. Nevitt Sanford. 1950. The authoritarian personality. New York: Harper.

Aerts, Saskia, Dewaele, Alexis, Cox, Nele and Mieke Van Houtte. 2014. "Homonegativity in the Technical and Vocational Track: A Survey of Secondary School Students in Flanders." Journal of LGBT Youth 11(4): 364-387.

Agnew, Christopher R., Thompson, Valda D. and Stanely O. Gaines. 2000. "Incorporating proximal and distal influences on prejudice: testing a general model across outgroups." Personality and Social Psychology Bulletin 26(4): 403-18.

Akrami, Nazar, Ekehammar, Bo and Robin Bergh. 2011. "Generalized prejudice: common and specific components." Psychological Science 22(1): 57-59.

Allport, Gordon W. 1958. The nature of prejudice. New York: Doubleday Anchor.

Altemeyer, Bob. 1998. "The other "authoritarian personality".” Advances in Experimental Social Psychology 30: 47-92.

Altemeyer, Bob and Bruce Hunsberger. 1992. "Authoritarianism, religious fundamentalism, quest, and prejudice." International Journal for the Psychology of religion 2: 113-133.

Asbrock, Frank, Sibley, Chris G. And John Duckitt. 2010. "Right-wing authoritarianism and social dominance orientation and the dimensions of generalized prejudice: a longitudinal test.” European Journal of Personality 24: 324-340. 
Bäckström, Martin and Fredrik Björklund. 2007. "Structural modeling of generalized prejudice: the role of social dominance, authoritarianism, and empathy." Journal of Individual Differences 28: 10-17.

Bergamaschi, Alessandro. 2013. "Adolescents and prejudice: A comparative study of the attitudes of two European adolescent populations regarding the issues that are raised by increasing cultural and religious pluralism." International Journal of Intercultural Relations 37(3): $302-312$.

Bierly, Margaret M. 1985. "Prejudice toward contemporary outgroups as a generalized attitude." Journal of Applied Social Psychology 15(2): 189-99.

Bilsky, Leora. 2009. "Muslim headscarves in France and army uniforms in Israel: A comparative study of citizenship as a mask." Patterns of Prejudice 43(4): 287-311.

Blalock, Hubert M. 1967. Toward a theory of minority-group relations. New York: John Wiley \& Sons.

Bleich, Erik. 2011. "What is Islamophobia and how much is there? Theorizing and measuring an emerging comparative concept.” American Behavioral Scientist 55(12): 1581-1600.

Blumer, Herbert. 1958. "Race prejudice as a sense of group position." The Pacific Sociological Review 1: 3-7.

Bobo, Lawrence and Vincent Hutchings. 1996. "Perceptions of racial group competition: Extending Blumer's theory of group position to a multiracial social context." American Sociological Review 6(61): 951-972.

Bobo, Lawrence. 1999. "Prejudice as group position: Microfoundations of a sociological approach to racism and race relations." Journal of Social Issues 3(55): 445-472.

Bourdieu, Pierre. 1984. Distinction: A social critique of the judgement of taste. London: Routlegde.

Bourdieu, Pierre. 1985. "The social space and the genesis of groups." Theory and Society 6(14), 423-744.

Bourdieu, P. (1990). The logic of practice. Cambridge: Polity Press. 
Bracke, Sarah. 2012. 'From 'saving women' to 'saving gays': Rescue narratives and their dis/continuities.” European Journal of Women's Studies 19(2), 237-252.

Bratt, Christopher. 2005. "The structure of attitudes toward non-western immigrant groups: second-order factor analysis of attitudes among Norwegian adolescents." Group Processes \& Intergroup Relations 8(4): 447-69.

Choma, Becky L. and Gordon Hodson. 2008. "And so the pendulum swings. A framework for conceptualizing the causes of prejudice.” Pp. 1-25 in The Psychology of Modern Prejudice, edited by Melanie A. Morrison and Todd G. Morrison. New York: Nova Science Publishers.

Connell, R W. .2005. Masculinities. Cambridge: Polity.

Dewaele, Alexis, Van Houtte, Mieke, Cox, Nele and John Vincke. 2013. "From Coming Out to Visibility Management-A New Perspective on Coping With Minority Stressors in LGB Youth in Flanders." Journal of Homosexuality 60(5), 685-710.

Duckitt, John. 2006. "Differential effects of right-wing authoritarianism and social dominance orientation on outgroup attitudes and their mediation by threat from and competitiveness to outgroups.” Personality and Social Psychology Bulletin 32(5): 684-696.

Duckitt, John and Chris G. Sibley. 2007. "Right Wing Authoritarianism, Social Dominance Orientation and The Dimensions of Generalized Prejudice." European Journal of Personality 21: 113-130.

Ekehammar, Bo, Akrami, Nazar, Gylje, Magnus and Ingrid Zakrisson. 2004. "What matters most to prejudice: big five personality, social dominace orientation, or right-wing authoritarianism?" European Journal of Personality 18: 463-82.

Fekete, Liz. 2009. A suitable enemy: Racism, migration and Islamophobia in Europe. New York: Pluto Press.

Fiske, Susan T., Cuddy, Amy C., Glick, Peter and Jun Xu. 2002. "A model of (often mixed) stereotype content: Competence and warmth respectively follow from perceived status and competition.” Journal of Personality and Social Psychology 82(6): 878-902. 
Ganzeboom, Harry and Donald J. Treiman. 1996. "Internationally comparable measures of occupational status for the 1988 International Standard Classification of Occupations." Social Science Research 25: 201-239.

Hagendoorn, Louk. 1995. "Intergroup Biases in Multiple Group Systems: The Perception of Ethnic Hierarchies.” European Review of Social Psychology 6: 199-228.

Herek, Gregory M. 1988. 'Heterosexuals' attitudes toward lesbians and gay men: Correlates and gender differences." The Journal of Sex Research 25(4): 451-477.

Hjerm, Mikael and Kikuko Nagayoshi. 2011. "The composition of the minority population as a threat: Can real economic and cultural threats explain xenophobia." International Sociology 26(6): 815-843.

Hodson, Gordon and Kristof Dhont. 2015. "The person-based nature of prejudice: Individual difference predictors of intergroup negativity." European Review of Social Psychology 26(1): $1-42$.

Hövermann, Andrea, Gross, Eva M., Zick, Andreas and Steven F. Messner. 2015. “Understanding the devaluation of vulnerable groups: A novel application of Institutional Anomie Theory." Social Science Research 52: 408-421.

Hudson, Walter W. and Wendell A. Ricketts. 1980. "A Strategy for the Measurement of Homophobia.” Journal of Homosexuality 5(4): 357-372.

Hunsberger, Bruce and Lynne M. Jackson. 2005. "Religion, meaning, and prejudice.” Journal of Social Issues 61: 807-826.

Key, Valdimer O. 1949. Southern politics in state and nation. New York: Knopf.

Kinder, Donald. R. and Cindy M. Kam. 2010. Us against them. Ethnocentric foundations of American opinion. Chicago: The University of Chicago Press.

Koopmans, Ruud. 2015. "Religious fundamentalism and hostility against out-groups: a comparison of Muslims and Christians in Western Europe." Journal of Ethnic and Migration Studies 44(1): 33-57.

Kumar, Deepa. 2012. Islamophobia and the politics of empire. Chicago: Haymarket Books. 
Kunovich, Robert M. 2004. "Social structural position and prejudice: an exploration of crossnational differences in regression slopes." Social Science Research 33(1): 20-44.

Meer, Nasar. 2013. "Semantics, scales and solidarities in the study of antisemitism and Islamophobia.” Ethnic and Racial Studies 36(3): 500-515.

Merton, Robert K. 1968 [1957]. Social theory and social structure. New York: The Free Press.

Meuleman, B., Davidov, E. \& Billiet, J. (2009). Changing attitudes toward immigration in Europe, 2002-2007: a dynamic group conflict theory approach. Social Science Research, 38(2): 352-365.

Pargament, Kenneth I., Trevino, Kelley, Mahoney, Anette and Israela Silberman. 2007. “They killed our lord: the perception of Jews as desecrator of Christianity as a predictor of antiSemitism." Journal of the Scientific Study of Religion 46(2): 143-158.

Plummer, David. 1999. One of the Boys: Masculinity, Homophobia, and Modern Manhood. New York: Harrington Park Press.

Podsakoff, Philip M., MacKenzie, Scott B., Lee, Jeong-Yeon and Nathan P. Podsakoff. 2003. "Common method biases in behavioral research: A critical review of the literature and recommended remedies." Journal of Applied Psychology 88(5): 879-903.

Ray, John J. and F.H. Lovejoy. 1986. "The generality of racial prejudice.” The Journal of Social Psychology 126(4): 563-64.

Riek, Blake M., Mania, Eric. W. and Samuel L. Gaertner. 2006. "Intergroup threat and outgroup attitudes: a meta-analytic review." Personality and Social Psychology Review 10(4): 336353.

Runciman, Walter G. 1966. Relative deprivation and social justice: A study of attitudes to social inequality in twentieth century England. Berkeley: University of California Press.

Schiefer, David. 2013. "Cultural values and group-related attitudes: A comparison of individuals with and without migration background across 24 countries." Journal of Cross-Cultural Psychology 44(2): 245-262. 
Schiffer Sabine and Constantin Wagner. 2011. "Anti-Semitism and Islamophobia - new enemies, old patterns." Race \& Class 52: 377-384.

Schneider, Anne and Helen Ingram. 1993. "Social construction of target populations: Implications for politics and policy." American political science review 87(02): 334-347.

Spruyt, Bram and Mark Elchardus. 2012. "Are anti-muslim feelings more widespread than antiforeigner feelings? Evidence from two split-sample experiments." Ethnicities 12(6): 800820.

Stephan, Walter G., Ybarra, Oscar, Martínez Martínez, Carmen, Schwarzwald, Joseph and Michal Tur-Kaspa. 1998. "Prejudice toward immigrants to Spain and Israel. An integrated threat theory analysis." Journal of Cross-Cultural Psychology 29(4): 559-576.

Strabac, Zan and Ola Listhaug. 2008. "Anti-Muslim prejudice in Europe: A multi-level analysis of survey data from 30 countries." Social Science Research 37: 268-286.

Swyngedouw, Marc. 1995. "The 'threatening immigrant' in Flanders 1930-1980: Redrawing the social space." New Community 21(3): 325-340.

Taras, Ray. 2013. “'Islamophobia never stands still': race, religion, and culture.” Ethnic and Racial Studies 36(3): 417-433.

Thornton, Arland, Alwin, Duane F. and Donald Camburn. 1983. "Causes and Consequences of Sex-Role Attitudes and Attitude Change." American Sociological Review 48(2): 211-27.

Whitley, Bernard E. 2009. "Religiositiy and attitudes towards lesbians and gay men: a metaanalysis." The International Journal for the Psychology of Religion 19(1): 21-38.

Zick, Andreas, Küpper, Beate and Andreas Hövermann. 2011. Intolerance, prejudice and discrimination. A European Report. Berlin: Friedrich-Ebert-Stiftung.

Zick, Andreas, Wolf, Carina, Küpper, Beate, Davidov, Eldad, Schmidt, Peter and Wilhelm Heitmeyer. 2008. "The syndrome of group-focused enmity: The interrelation of prejudices tested with multiple cross-sectional and panel data." Journal of Social Issues 64(2): 363383. 
${ }^{\mathrm{i}}$ Unfortunately, our model only assumes random measurement error, and does not take systematic measurement error into account. This has important consequences for the distinction between common and specific prejudices. Insofar the different items are affected by the same bias -i.e. so-called Common Method Variance (CMV; Podsakoff et al. 2003)- the common factor will absorb the systematic measurement errors. Thus, the second-order CFA approach overestimates rather than underestimates the commonality of prejudices - a fact that is often neglected in empirical research. 
Table 1. Overview of hypotheses regarding the common and specific determinants of prejudices

\begin{tabular}{|l|c|c|c|c|c|}
\hline & $\begin{array}{c}\text { General } \\
\text { pattern }\end{array}$ & \multicolumn{3}{|c|}{ Deviations from the general pattern } \\
\hline & & & & \\
& & & & & \\
& & & & & \\
\hline Gender (being male) & $+(\mathrm{H} 2)$ & $+(\mathrm{H} 11)$ & & & \\
\hline Old age & $+(\mathrm{H} 3)$ & & & & \\
\hline Low eduation & $+(\mathrm{H} 4)$ & & & & \\
\hline Low social class & $+(\mathrm{H} 5)$ & & $+(\mathrm{H} 15)$ & & \\
\hline Strong religious involvement & $+(\mathrm{H} 6)$ & $+(\mathrm{H} 12)$ & & & $+(\mathrm{H} 19)$ \\
\hline Authoritarianism & $+(\mathrm{H} 7)$ & & & & \\
\hline Relative deprivation & $+(\mathrm{H} 8)$ & $-(\mathrm{H} 13)$ & $+(\mathrm{H} 16)$ & & \\
\hline Gender traditionalism & $+(\mathrm{H} 9)$ & $+(\mathrm{H} 14)$ & & $-(\mathrm{H} 18)$ & \\
\hline
\end{tabular}

Table 2. Fit indices for various decompositions of the common and specific components of prejudice

\begin{tabular}{|c|l|c|c|c|c|c|}
\hline & & $\begin{array}{c}\text { Chi- } \\
\text { square }\end{array}$ & Df & RMSEA & CFI & TLI \\
\hline $\begin{array}{c}\text { Model } \\
1\end{array}$ & $\begin{array}{l}\text { Specific \& common } \\
\text { components: second-order } \\
\text { factor model }\end{array}$ & 602.48 & 114 & 0.065 & 0.968 & 0.962 \\
\hline $\begin{array}{c}\text { Model } \\
2\end{array}$ & $\begin{array}{l}\text { Only specific components - 4 } \\
\text { unrelated first-order factors }\end{array}$ & 4669.59 & 119 & 0.195 & 0.705 & 0.663 \\
\hline $\begin{array}{c}\text { Model } \\
3\end{array}$ & $\begin{array}{l}\text { Only common component - all } \\
\text { items load on a single factor }\end{array}$ & 4761.76 & 119 & 0.197 & 0.699 & 0.656 \\
\hline
\end{tabular}

Table 3. Common and specific components of the four forms of prejudice

\begin{tabular}{|c|c|c|c|}
\hline & 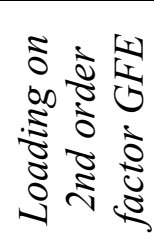 & $\begin{array}{l}\stackrel{\vec{\Xi}}{\vdots} \\
\vdots \\
\vdots \\
\vdots \\
\vdots\end{array}$ & 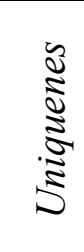 \\
\hline Homonegativity & 0.54 & 0.29 & 0.71 \\
\hline Anti-immigrant attitudes & 0.86 & 0.74 & 0.26 \\
\hline Anti-Semitism & 0.53 & 0.28 & 0.72 \\
\hline
\end{tabular}




\begin{tabular}{|l|l|l|l|} 
Islamophobia & 0.60 & 0.36 & 0.64 \\
\hline
\end{tabular}

Table 4. Direct effects of structural and attitudinal characteristics on forms of prejudice $(\mathrm{N}=1007)$

\begin{tabular}{|c|c|c|c|c|c|c|c|c|c|c|}
\hline & \multicolumn{2}{|c|}{$G F E$} & \multicolumn{2}{|c|}{ Homonegativity } & \multicolumn{2}{|c|}{\begin{tabular}{|c|}
$\begin{array}{c}\text { Anti-immigrant } \\
\text { attitudes }\end{array}$ \\
\end{tabular}} & \multicolumn{2}{|c|}{ Islamophobia } & \multicolumn{2}{|c|}{ Anti-semitism } \\
\hline & Par.Est. & $p$-value & Par.Est. & $p$-value & Par.Est. & $p$-value & Par.Est. & $p$-value & Par.Est. & $p$-value \\
\hline \multicolumn{11}{|l|}{ Gender } \\
\hline \multicolumn{11}{|l|}{ Male (ref.cat.) } \\
\hline \multirow[t]{2}{*}{ Female } & -0.143 & 0.082 & -0.169 & 0.013 & & & & & & \\
\hline & -0.155 & 0.009 & 0.178 & 0.000 & & & 0.183 & 0.000 & & \\
\hline \multicolumn{11}{|l|}{ Education } \\
\hline \multicolumn{11}{|l|}{ Lower secundary (ref.cat.) } \\
\hline Higher secundary & 0.036 & 0.707 & & & & & & & & \\
\hline Tertiary & -0.039 & 0.718 & & & & & & & & \\
\hline \multicolumn{11}{|l|}{ Social class } \\
\hline $\begin{array}{r}\text { Secrive class / self- } \\
\text { employed }\end{array}$ & 0.165 & 0.280 & & & -0.068 & 0.538 & & & & \\
\hline Non-manual workers & 0.169 & 0.117 & & & -0.182 & 0.015 & & & & \\
\hline \multicolumn{11}{|l|}{ Manual workers (ref.cat.) } \\
\hline Never worked & -0.018 & 0.904 & & & -0.156 & 0.209 & & & & \\
\hline \multicolumn{11}{|l|}{ Religious involvement } \\
\hline \multicolumn{11}{|l|}{ Regular church attendance } \\
\hline $\begin{array}{r}\text { Occasional Church } \\
\text { Attendance }\end{array}$ & 0.070 & 0.527 & -0.329 & 0.002 & & & & & -0.236 & 0.034 \\
\hline Non-believers and atheists & 0.039 & 0.661 & -0.181 & 0.015 & & & & & -0.025 & 0.776 \\
\hline Authoritarianism & 0.594 & 0.000 & & & & & & & & \\
\hline Relative deprivation & 0.297 & 0.000 & -0.158 & 0.001 & & & 0.109 & 0.009 & & \\
\hline Traditionalism & 0.130 & 0.007 & 0.364 & 0.000 & & & -0.207 & 0.000 & & \\
\hline Explained variance & \multicolumn{2}{|c|}{$58.9 \%$} & \multicolumn{2}{|c|}{$53.9 \%$} & \multicolumn{2}{|c|}{$69.8 \%$} & \multicolumn{2}{|c|}{$50.1 \%$} & \multicolumn{2}{|c|}{$28.3 \%$} \\
\hline $\mathrm{Ch}$ & -square: 1 & 226.29; D & f: $506 ; \mathrm{RI}$ & MSEA: 0. & 038; CFI: & $0.967 ; 7$ & I: 0.961 & & & \\
\hline
\end{tabular}

Note: The parameters displayed are semi-standardized when the independent variable is a dummy (thus representing the difference with the reference category in terms of standard deviations of the dependent variable) and fully standardized in all other cases. The analysis is weighted for gender, age and education. 
Table 5. Total effects of structural and attitudinal characteristics on forms of prejudice $(\mathrm{N}=1007)$

\begin{tabular}{|c|c|c|c|c|c|c|c|c|c|c|}
\hline & \multicolumn{2}{|c|}{$G F E$} & \multicolumn{2}{|c|}{ Homonegativity } & \multicolumn{2}{|c|}{$\begin{array}{c}\text { Anti-immigrant } \\
\text { attitudes }\end{array}$} & \multicolumn{2}{|c|}{ Islamophobia } & \multicolumn{2}{|c|}{ Anti-semitism } \\
\hline & Par.Est. & $p$-value & Par.Est. & $p$-value & Par.Est. & $p$-value & Par.Est. & $p$-value & Par.Est. & $p$-value \\
\hline \multicolumn{11}{|l|}{ Gender } \\
\hline \multicolumn{11}{|l|}{ Male (ref.cat.) } \\
\hline Female & -0.087 & 0.303 & -0.344 & 0.000 & -0.072 & 0.303 & 0.019 & 0.742 & -0.046 & 0.306 \\
\hline Age & 0.067 & 0.227 & 0.294 & 0.000 & 0.055 & 0.221 & 0.178 & 0.000 & 0.036 & 0.221 \\
\hline \multicolumn{11}{|l|}{ Education } \\
\hline \multicolumn{11}{|l|}{ Lower secundary (ref.cat.) } \\
\hline Higher secundary & -0.221 & 0.040 & -0.129 & 0.045 & -0.182 & 0.037 & -0.137 & 0.068 & -0.117 & 0.040 \\
\hline Tertiary & -0.682 & 0.000 & -0.350 & 0.000 & -0.562 & 0.000 & -0.449 & 0.000 & -0.363 & 0.000 \\
\hline \multicolumn{11}{|l|}{ Social class } \\
\hline Secrive class / self-employed & -0.186 & 0.239 & -0.112 & 0.223 & -0.221 & 0.010 & -0.118 & 0.255 & -0.099 & 0.235 \\
\hline Non-manual workers & 0.008 & 0.945 & -0.016 & 0.813 & -0.176 & 0.029 & 0.011 & 0.888 & 0.004 & 0.945 \\
\hline \multicolumn{11}{|l|}{ Manual workers (ref.cat.) } \\
\hline Never worked & -0.002 & 0.991 & 0.177 & 0.053 & -0.157 & 0.224 & -0.110 & 0.282 & -0.001 & 0.991 \\
\hline \multicolumn{11}{|l|}{ Religious involvement } \\
\hline \multicolumn{11}{|l|}{ Regular church attendance } \\
\hline $\begin{array}{r}\text { Occasional Church } \\
\text { Attendance }\end{array}$ & 0.130 & 0.319 & -0.330 & 0.002 & 0.107 & 0.316 & 0.124 & 0.166 & -0.167 & 0.130 \\
\hline Non-believers and atheists & -0.077 & 0.423 & -0.328 & 0.000 & -0.063 & 0.419 & 0.014 & 0.836 & -0.066 & 0.455 \\
\hline Authoritarianism & 0.594 & 0.000 & 0.288 & 0.000 & 0.489 & 0.000 & 0.386 & 0.000 & 0.316 & 0.000 \\
\hline Relative deprivation & 0.297 & 0.000 & -0.014 & 0.730 & 0.245 & 0.000 & 0.303 & 0.000 & 0.158 & 0.000 \\
\hline Traditionalism & 0.130 & 0.007 & 0.427 & 0.000 & 0.107 & 0.004 & -0.122 & 0.005 & 0.069 & 0.005 \\
\hline Explained variance & \multicolumn{2}{|c|}{$58.9 \%$} & \multicolumn{2}{|c|}{$53.9 \%$} & \multicolumn{2}{|c|}{$69.8 \%$} & \multicolumn{2}{|c|}{$50.1 \%$} & \multicolumn{2}{|c|}{$28.3 \%$} \\
\hline \multicolumn{11}{|c|}{ Chi-square: 1226.29; Df: 506; RMSEA: 0.038; CFI: 0.967; TLI: 0.961} \\
\hline
\end{tabular}

Note: The parameters displayed are semi-standardized when the independent variable is a dummy (thus representing the difference with the reference category in terms of standard deviations of the dependent variable) and fully standardized in all other cases. The analysis is weighted for gender, age and education. 
Figure 1. Typology of out-groups according to the nature of threat posed

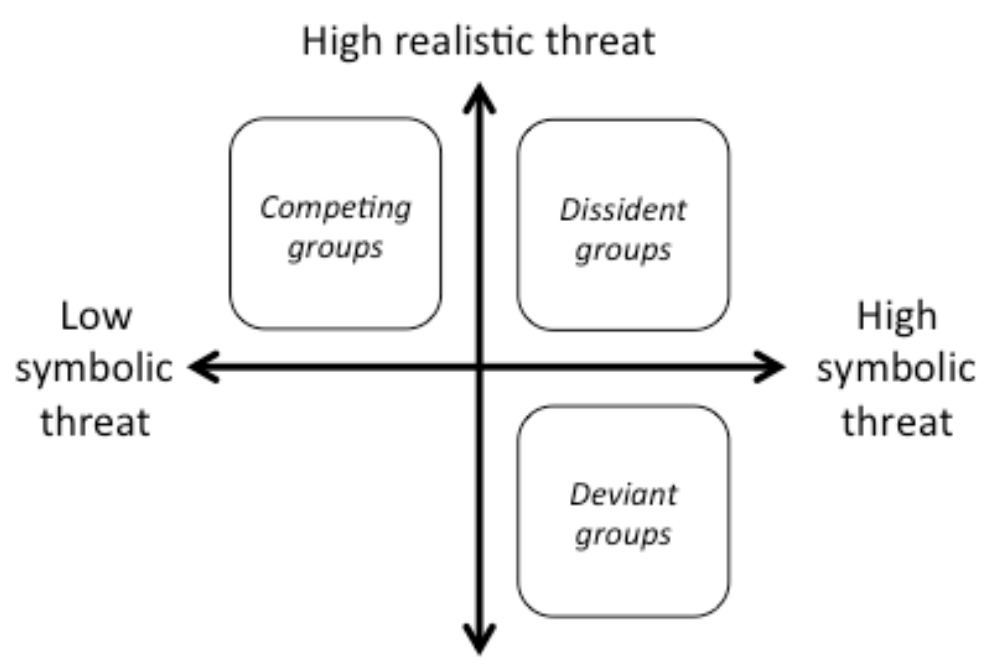

Low realistic threat 
Figure 2. Second-order factor model with standardized factor loadings ( $\mathrm{N}=1007)$

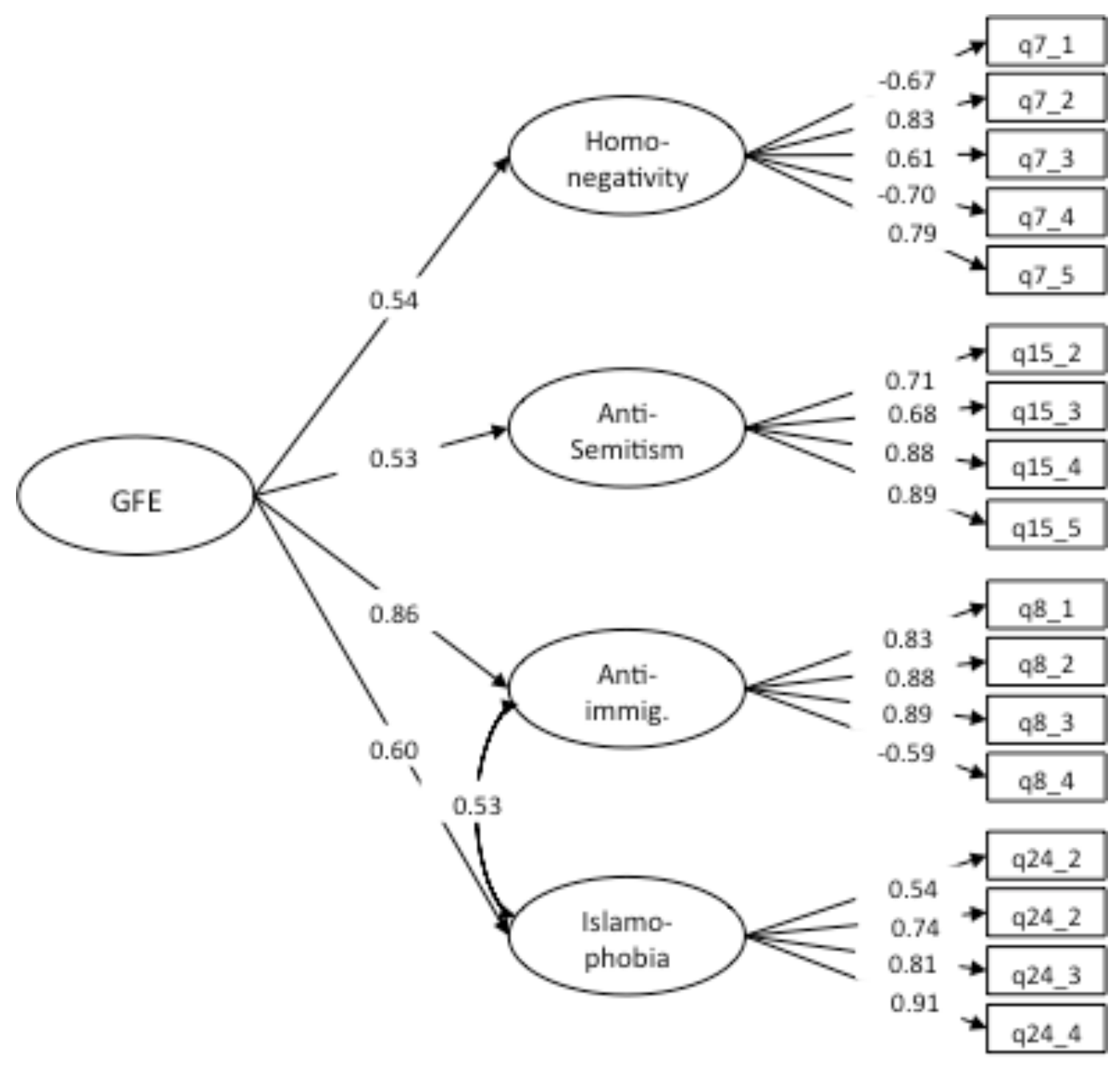

Chi-square: 602.48 Df: 114 RMSEA: 0.065 CFI: 0.968 TLI: 0.962 
Figure 3. GFE and forms of prejudice explained by means of structural and attitudinal predictors significant direct effects

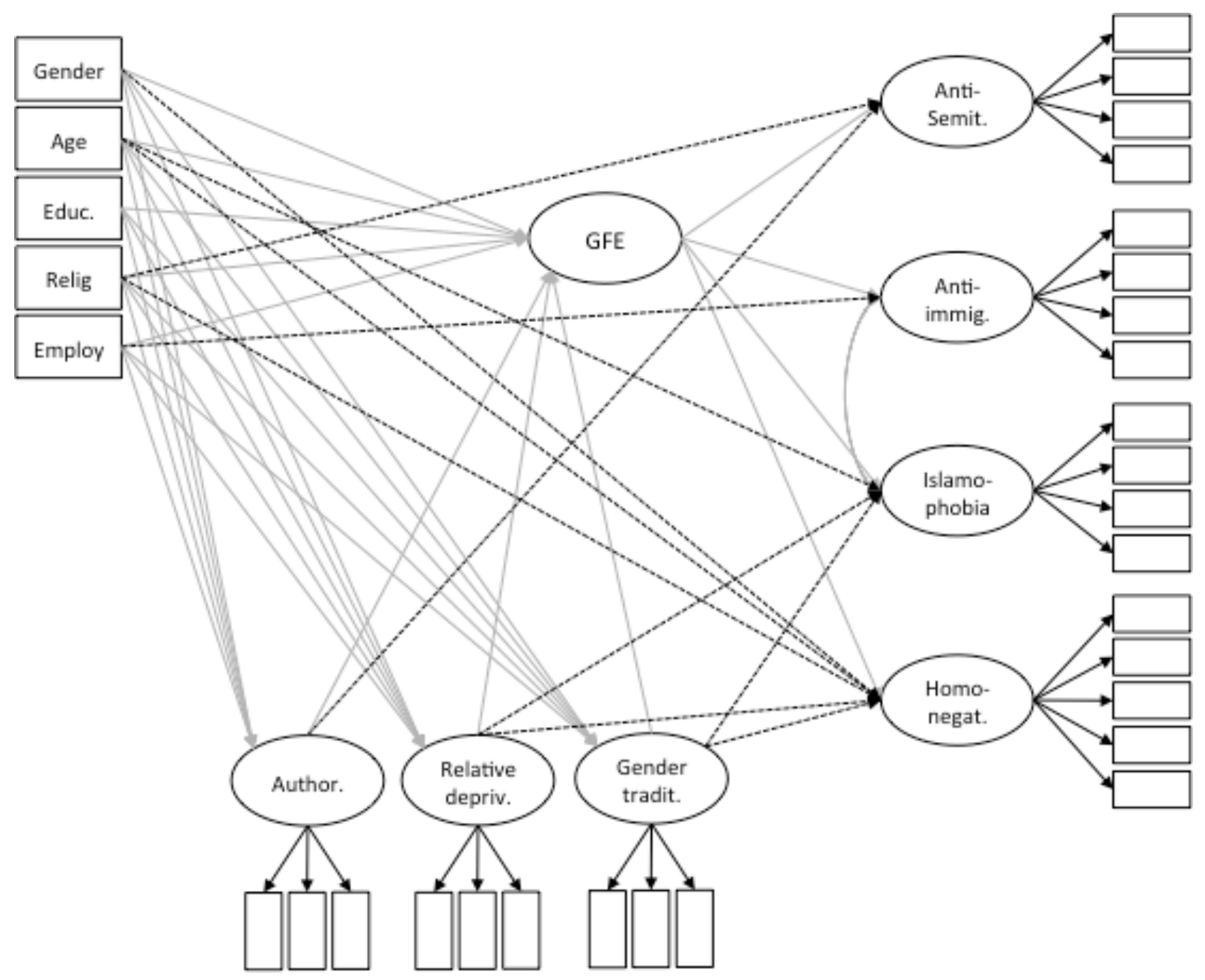

Chi-square: 1408.73 Df: 505 RMSEA: 0.042 CFI: 0.968 TLI: 0.962

Note: Direct arrows from predictors on first-order prejudices are striped. 
Appendix 1: CFA results for the specific prejudice factors

\begin{tabular}{|c|c|c|c|c|c|}
\hline & & 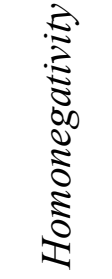 & 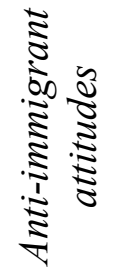 & 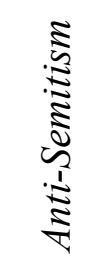 & 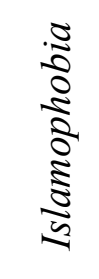 \\
\hline \multicolumn{6}{|c|}{ Standardized factor loadings } \\
\hline q7_1 & $\begin{array}{l}\text { Children should learn that being homosexual } \\
\text { is completely normal }\end{array}$ & -0.67 & & & \\
\hline $\mathrm{q} 7 \_2$ & $\begin{array}{l}\text { Equal rights for homosexuals is a threat for } \\
\text { our norms and values }\end{array}$ & 0.83 & & & \\
\hline q7_3 & $\begin{array}{l}\text { Homosexual men should not make such a fuss } \\
\text { about their sexual orientation }\end{array}$ & 0.61 & & & \\
\hline q7 4 & $\begin{array}{l}\text { Gay and straight people should be treated } \\
\text { equally }\end{array}$ & -0.70 & & & \\
\hline q7 5 & Lesbian women are abnormal & 0.79 & & & \\
\hline q8_1 & Migrants are generally not trustworthy & & 0.83 & & \\
\hline q8_2 & $\begin{array}{l}\text { Migrants come here to profit from our social } \\
\text { security model }\end{array}$ & & 0.88 & & \\
\hline q8_3 & $\begin{array}{l}\text { Migrants are a threat to our culture and } \\
\text { customs }\end{array}$ & & 0.89 & & \\
\hline q8_4 & $\begin{array}{l}\text { The presence of different cultures is an } \\
\text { enrichment of our society }\end{array}$ & & -0.59 & & \\
\hline $\mathrm{q} 152$ & Jews have too much influence in our country & & & 0.70 & \\
\hline q15_3 & Jews think they are better than all others & & & 0.68 & \\
\hline$q 154$ & One should avoid Jews; you cannot trust them & & & 0.88 & \\
\hline$q 15 \quad 5$ & Jews are only after money & & & 0.88 & \\
\hline $\mathrm{q} 24 \quad 2$ & Muslim men dominate Muslim women & & & & 0.55 \\
\hline q24 3 & $\begin{array}{l}\text { When it comes down, Islamic countries will } \\
\text { turn against Europe }\end{array}$ & & & & 0.75 \\
\hline $\mathrm{q} 24 \_4$ & $\begin{array}{l}\begin{array}{l}\text { Islamic history and culture is more violent } \\
\text { than others }\end{array} \\
\end{array}$ & & & & 0.81 \\
\hline q24_5 & Islamic values are a threat to Europe & & & & 0.91 \\
\hline \multicolumn{6}{|c|}{ Correlations between factors } \\
\hline & Homonegativity & 1.00 & & & \\
\hline & Anti-immigrant attitudes & 0.47 & 1.00 & & \\
\hline & Anti-Semitism & 0.29 & 0.45 & 1.00 & \\
\hline & Islamophobia & 0.31 & 0.73 & 0.33 & 1.00 \\
\hline ode & Chi-square: 622.03 ; Df: 113; RMSEA: 0. & $067 ; \mathrm{C}$ & 0.967 & $\mathrm{I}: 0.96$ & \\
\hline
\end{tabular}


Appendix 2: CFA results for the attitudinal predictors of prejudice

\begin{tabular}{|c|c|c|c|c|}
\hline & & 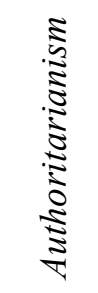 & 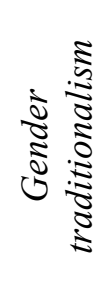 & 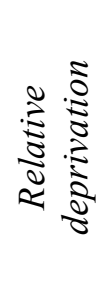 \\
\hline \multicolumn{5}{|c|}{ Standardized factor loadings } \\
\hline $\mathrm{q} 12 \_3$ & $\begin{array}{l}\text { Most of our social problems could be solved, if we } \\
\text { could somehow get rid of the immoral, crooked } \\
\text { people }\end{array}$ & 0.63 & & \\
\hline $\mathrm{q} 12 \_4$ & $\begin{array}{l}\text { Obedience and respect for authority are the two most } \\
\text { important virtues children have to learn }\end{array}$ & 0.72 & & \\
\hline q12 5 & $\begin{array}{l}\text { Laws should become stricter, because too much } \\
\text { freedom is not good for people }\end{array}$ & 0.69 & & \\
\hline $\mathrm{q} 14 \_1$ & $\begin{array}{l}\text { It isn't really as important for a girl to get a good } \\
\text { education as it is for a boy }\end{array}$ & & 0.81 & \\
\hline $\mathrm{q} 142$ & In general, boys can be brought up freer than girls & & 0.72 & \\
\hline q14_3 & $\begin{array}{l}\text { It's unnatural if women give guidance to men in a } \\
\text { company }\end{array}$ & & 0.87 & \\
\hline q14 4 & $\begin{array}{l}\text { It is the most natural thing for a man to be a } \\
\text { breadwinner and for a women to take care of the } \\
\text { household and the children }\end{array}$ & & 0.70 & \\
\hline $\mathrm{q} 30 \_1$ & $\begin{array}{l}\text { If we need something from the government, people } \\
\text { like me have to wait longer than others. }\end{array}$ & & & 0.87 \\
\hline $\mathrm{q} 30 \_2$ & $\begin{array}{l}\text { People like me are being systematically neglected, } \\
\text { whereas other groups received more than they } \\
\text { deserve. }\end{array}$ & & & 0.94 \\
\hline $\mathrm{q} 30 \_3$ & $\begin{array}{l}\text { In times of economic crises people like me are always } \\
\text { the first victims. }\end{array}$ & & & 0.82 \\
\hline \multicolumn{5}{|c|}{ Correlations between factors } \\
\hline & Authoritarianism & 1.00 & & \\
\hline & Gender traditionalism & 0.37 & 1.00 & \\
\hline & Relative deprivation & 0.42 & 0.26 & 1.00 \\
\hline
\end{tabular}

